\title{
ORAL AND PERIODONTAL HEALTH IN CHRONIC USERS OF PSYCHOACTIVE SUBSTANCES
}

\author{
Kosta Todorović1,2, Marija Bojović ${ }^{3}$, Milica S. Petrović ${ }^{4}$, Radmila \\ Obradović ${ }^{3}$, Saša Bubanj ${ }^{5}$, Rade Jovanović6, Ivan Minić4, Ljiljana Kesić2,3
}

\author{
University of Niš, Faculty of Medicine, Department of Oral surgery, Niš, Serbia1 \\ Clinic of dentristry, Niš, Serbia2 \\ University of Nis, Faculty of Medicine, Department of Periodontology and Oral Medicine, Niš, \\ Serbia3 \\ University of Niš, Faculty of Medicine, Doctoral study student, Niš, Serbia4 \\ University of Niš, Faculty of Sport and Physical Education, Niš,Serbia 5 \\ University of Niš, Faculty of Sport and Physical Education, Doctoral study student, Niš, Serbia6
}

Contact: Kosta Todorović

Boulevard dr Zorana Đinđića 81, 18000 Niš,Serbia

e-mail: kosta_todorovic@yahoo.com

The number of drug addicts increases rapidly, especially among the young. In Serbia, there are about 80.000 drug addicts. Long-term addicts experience changes in the mouth cavity.

The aim of this investigation was to determine the level of oral hygiene among the users of psychoactive substances while them and afterwards.

This investigation was performed on 26 patients of the Addiction Treatment Hospital "St. George" in Niš. After an oral and periodontal clinical examination, the examinees were asked to fill in the questionnaire concerning the level of their oral hygiene.

Of the total of 26 patients, 24 (92\%) were male, aged 27.9 years on the average. They had the history of use of narcotics for $7.38 \pm 3.0$ years before the start of therapy. Heroin was used statistically significantly more than all other substances $(p<0.001)$, while snorting was the most common way to consume it $(p<0.001)$.

Clinical examinations confirmed that the majority of examinees had gingivitis - 23 $(88.46 \%)$, which was a significantly more common diagnosis compared to periodontal disease $(p<0.05)$.

While using narcotics, 24 examinees (92.31\%) used toothbrushes, versus $26(100 \%)$ in the period of abstinence. Five examinees (19.23\%) used some other oral hygiene accessories, while in the period of abstinence $16(61.54 \%)$ examinees used these $(p<0.01)$. The daily frequency of tooth brushing increased $(p<0.05)$. There were 22 active smokers $(84,62 \%)$ among the examinees, but this number fell to $16(61.54 \%)$ after giving up narcotics.

The most frequent oral diseases were gingivitis and periodontal disease at the time of drug addiction. Oral health was better in the period of abstinence than in the period of active addiction. It is an important fact that more drug addicts used toothbrushes in the period of abstinence than in the period of addiction. The role of doctors and dentists is very important, especially in the areas of motivation and education of these patients in oral health preservation. Acta Medica Medianae 2017;56(2) :64-69.

Key words: head and neck infections, complications, CT 